Western University

Scholarship@Western

Department of Economics Research Reports

Economics Working Papers Archive

1970

\title{
Technical Progress and Relative Stability of a Two- Sector Model of Economic Growth
}

Raveendra Batra

Follow this and additional works at: https://ir.lib.uwo.ca/economicsresrpt

Part of the Economics Commons

Citation of this paper:

Batra, Raveendra. "Technical Progress and Relative Stability of a Two-Sector Model of Economic Growth." Department of Economics Research Reports, 7031. London, ON: Department of Economics, University of Western Ontario (1970). 
RESEARCH REPORT 7031

TECHNICAL PROGRESS AND RELATIVE STABILITY

OF A TWO-SECTOR MODEL OF ECONOMIC GROWTH

\author{
by \\ Raveendra Batra
}

October, 1970 
Technical Progress and Relative Stability

of a Two-Sector Model of Economic Growth*

by

Raveendra Batra

In the recent spurt on the two-sector, two-factor neoclassical growth models, the consequences of technical progress for relative stability have not been fully analyzed. The only studies that deal with this problem are those of Findlay [7], Takayama [10] and the present author [3] ${ }^{1}$. In these papers it has been shown that technical progress leaves unchanged the conditions for the existence and the stability of the balanced growth path, defined by the constancy and the equality of the rates of growth of labor and capital only if (1) it occurs in the consumption-goods sector, and (2) it is Hicks- or Harrod-neutral.

Recognizing the limited significance of this result, Takayama goes a bit further and utilizes the concept of "equilibrium growth path," which he defines as one where capital stock grows faster than labor by a constant rate. He then shows that if (1) the consumption-goods sector is capitalintensive relative to the capital-goods sector, or (2) the elasticity of substitution in the capital-goods sector is at least equal to unity, the equilibrium growth path is stable even if technical progress occurs in the

*This paper is a generalized version of our results in [3]. The financial support for this research came from a summer-grant by the Graduate School of Research at the Southern Illinois University.

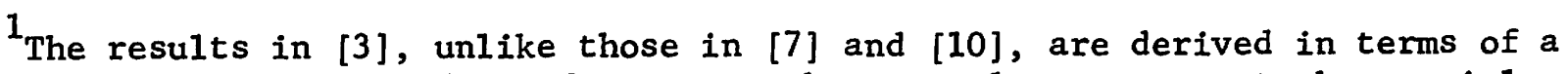
dynamic model of fixed coefficients. These results turn out to be special cases of our conclusions obtained in this paper where production coefficients are not kept constant. 
capital-goods sector, provided it is Harrod-neutral. However, in the 11terature on two-sector growth models without technical progress, the balanced growth path has been shown to be stable under less restrictive conditions. For example Drandakis [6] and Amano [1] have proved that the twosector growth model is relatively stable if the elasticity of substitution in any sector equals or exceeds unity. In addition, the present author [4] has derived a still weaker set of sufficient conditions by showing that the relative stability requires the elasticity of substitution in any sector to be a positive fraction greater than or equal to the relative share of labor In the other sector. One purpose of this paper is to show that for the equilibrium growth Dath to be stable, the set of sufficient conditions does not have to be as strong as that proposed by Takayama. Secondly, we show that the equilibrium growth path is stable even if technical progress in any sector is Hicks-neutral. To facflitate our analysis, we give a more general connotation to the equilibrium growth path by defining it as the path where the rate of growth of capital differs from the exogenously given rate of growth of labor by a constant rate, the difference being positive or negative. In this way, we show that the equilibrium growth path is stable even if capital stock grows slower than labor by a constant rate.

\section{The Model and Some Key Relations}

It is assumed that the economy consists of two sectors of production, the consumption-goods sector $\left(Y_{2}\right)$ and the capital-goods sector $\left(Y_{1}\right)$, which, in the process of production, utilize two factors, capital (K) and labor (L). Perfect competition, constant returns to scale, diminishing returns along the isoquants, full employment of factors, inelastlc factor supplies and perfect factor mobllity are also assumed. Capital and labor are homogeneous and can be used in any sector. Workers consume all their income and capitalists save a part of their income. 
The two production functions are:

(1) $Y_{1}=F_{1}\left(K_{1}, L_{1}, t\right)=L_{1} f_{1}\left(k_{1}, t\right)$

(2) $Y_{2}=F_{2}\left(K_{2}, L_{2}, t\right)=L_{2} f_{2}\left(k_{2}, t\right)$

where $K_{i}, L_{i}$ are respectively the capital and labor inputs and $k_{1}=K_{1} / L_{1}$, is the capital/labor ratio in the $1^{\text {th }}$ sector $(1=1,2)$, and $t$ is a shfft parameter representing the technological level of the economy.

Let $u_{i}$ and $v_{i}$ respectively denote the marginal productivity of capital and labor in the $i^{\text {th }}$ sector. Then

$$
\begin{array}{ll}
v_{i}=f_{i}^{\prime}=\frac{\partial f_{i}}{\partial k_{i}} & \left(f_{i}^{\prime}=f_{i}^{\prime}\left(k_{i}\right)\right) \\
u_{1}=f_{i}-k_{i} f_{i}^{\prime} &
\end{array}
$$

It may be noted that all marginal productivities depend on factor-proportions and the shift parameter. It is assumed that $f_{i}^{\prime}>0$ and $f_{1}^{\prime \prime}<0$.

Under perfect competition, the price of each factor of production equals its marginal value product and is the same in both sectors. Let $w$ stand for the wage-rate, $r$ for the rental rate of capital and $P_{1}$ for the price of the $1^{\text {th }}$ commodity. Factor rewards can then be expressed as:

(3) $w=P_{1} u_{1}=P_{1}\left(f_{1}-k_{1} f_{1}^{\prime}\right)$

(4) $r=P_{i} v_{i}=P_{i} f_{i}^{\prime}$

(5) $\omega=\frac{w}{r}=\frac{u_{i}}{v_{i}}=\frac{f_{i}}{f_{i}^{\prime}}-k_{i}$

With full employment

(6) $f_{1}+f_{2}=1$

(7) ${ }^{\prime}{ }_{1} k_{1}+{ }^{\prime \prime} k_{2} k_{2}=k$

where $\rho_{1}=L_{1} / L$ and $k=K / L$.

Let $s$ denote the propensity to save of the capitalists. The saving-investment equilibrium requires that

(8) $P_{1} Y_{1}=s r K$ 
where $0<s<1$. It is assumed that 8 is constant. Let $\sigma_{1}$ be the elasticity of factor substitution in the $1^{\text {th }}$ sector. Then

(9) $\sigma_{1}=\frac{i k_{1}}{\partial \omega} \cdot \frac{\omega}{k_{1}}>0$.

Let $B_{i}$ denote the relative share of labor in the $1^{\text {th }}$ sector. Then

$$
B_{i}=\frac{L_{1} u_{1}}{Y_{1}}=1-\frac{k_{1} v_{1}}{Y_{1}}=\frac{\left(f_{1}-k_{1} f_{1}\right) f_{i}^{\prime}}{f_{1} f_{1}}=\frac{\omega}{\omega+k_{1}} \text {. }
$$

From the equations of production functions and equation (5), it is clear that (11) $k_{1}=k_{i}(w, t)$

From the Euler theorem with linear homogeneous functions:

(13) $P_{1} Y_{i}=w L_{1}+r K_{i}$

We now transform some of the production relations into variables of relative rates of change in order to obtain certain key relations which will be utilized in the subsequent analysis. Let the asterisk refer to the relative rate of change of a variable $\left(\mathrm{e} . \mathrm{g} ., \mathrm{k}^{*}=\mathrm{dk} / \mathrm{k}\right)$. Differentiating equations (1) and (2), we have:

(14) $Y_{1}^{*}=E_{1} L_{1}^{*}+\left(1-R_{1}\right) K_{1}^{+}+\alpha_{1}$

where $\alpha_{1}$ denotes the rate of growth of the $1^{\text {th }}$ output when the factor-input in the industry is kept constant ${ }^{2}\left(\alpha_{1}=\frac{1}{Y_{1}} \frac{\partial Y_{1}}{\partial t} d t\right)$. Differentiating equation (5), we have:

(15) $\omega^{\star}=w^{*}-r^{*}=u_{1}^{\star}-v_{1}^{*}$

Differentiating equation (11) we have:

(16) $k \neq=\nu_{1} u^{\star}+\lambda_{1}$

where $\lambda_{1}=\frac{1}{k_{1}} \frac{\partial k_{1}}{\partial t} d t$ is the relative rate of change in the capital/1abor ratio in the $i^{\text {th }}$ sector if there were only a change in the shift parameter. The partial derivative notation in obtaining $\lambda_{1}$ means that the factor prices

\footnotetext{
Equation (14) is obtained by first differentiating equations (1) and (2) and then utilizing equation (10).
} 
are kept constant. In other words, $\lambda_{1}$ is the Hicks-measure of technical

progress. ${ }^{3}$ Its sign indicates the nature of Hicks-technical progress.

If $\lambda_{1}=0$, techntcal progress is neutral; if $\lambda_{1}>0$, it is cap1tal-using;

if $\lambda_{1}<0$, it is capital-saving. Differentlating equations (12) and (13)

and substituting equation (10) we obtain the following two equations:

(18) $P_{i}^{*}+Y_{i}^{*}=k_{i}\left(w^{*}+L_{i}^{*}\right)+\left(1-K_{i}\right)\left(K_{i}^{*}+r^{*}\right)$

By combining equations (14), (15) and (17), we obtain:

$$
\omega^{*}=\frac{\alpha_{1}-v_{1}^{*}}{\beta_{1}}
$$

From equations (14), (15) and (18), we have:

(20) $P_{i}^{*}=k_{i} \omega^{\star}-\alpha_{i}+r^{*}$

We are now in a position to obtain a relationship between the Hicks-measure

of technical progress and the Harrod-measure of technical progress.

According to Harrod technical progress is neutral, capital-using or capitalsaving if, at the same rate of profit $\left(v_{1}\right)$, the value of the capital/output ratio remains constant, increases or decreases. Let $x_{1}$ be the value of the capital/output ratio in the $1^{\text {th }}$ sector. Then

$$
\begin{aligned}
& \text { (21) } x_{i}=\frac{P_{1} K_{1}}{P_{i} Y_{1}} \text {, or } \\
& \text { (22) } x_{i}^{*}=\left(P_{1}^{*}-P_{i}^{*}\right)+\left(K_{i}^{*}-Y_{i}^{*}\right)
\end{aligned}
$$

If the rate of profit is kept constant, then $v_{1}^{\star}=0$, so that from equation (19), (23) $\omega *=\frac{u_{1}}{i_{1}}$

From equation (16),

$$
(24)^{4} K_{i}^{*}=\sigma_{1} \omega^{*}+L_{i}^{*}+\lambda_{1}
$$

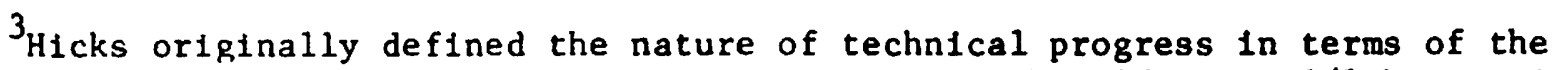
change in the marginal rate of substitution at the old capital/labor ratio. [t is well known that this definition is equivalent to that given in the text. This is also the classification used by Takayama [10].

${ }^{4}$ This is because $k_{1}^{*}=\left(K_{1} / L_{1}\right) *=K_{1}^{*}-L_{i}^{*}$. 
Then combining equation (14) with equation (24) we have:

(25) $K_{1}^{*}-Y_{1}^{*}=B_{1}\left(\sigma_{1} \omega^{*}+\lambda_{i}\right)-\alpha_{1}$

From equation (20) we obtain:

$$
P_{1}^{*}-\underset{1}{*}=\left(B_{1}-B_{1}\right) w^{*}-\left(\alpha_{1}-\alpha_{1}\right)
$$

Finally by substituting equations (23), (25) and (26) in equation (22) we obtain:

$(27)^{5} x_{i}^{*}=i_{i}\left[\frac{\alpha_{1}}{B_{1}}\left(O_{i}-1\right)+\lambda_{i}\right]=B_{i} H_{i}$,

(27a) where $H_{1}=\left[\frac{\alpha_{1}}{B_{1}}\left(a_{i}-1\right)+\lambda_{1}\right]$

From equation (27a), it is clear that technical progress in the Harrodsense is neutral, capital-using or capital-saving, according as $H_{1}=0$, $\mathrm{H}_{1}>0$ or $\mathrm{H}_{\mathrm{i}}<0$. Note that if there is no technical progress in the capital goods sector, $\alpha_{1} / B_{1}$ equals zero, so that $H_{2} \gtreqless 0$ depends on $\lambda_{2} \geqslant 0$. In other words, In the absence of any improvement in $Y_{1}$, the Hicks and the Harrod classifications of technical improvement in $Y_{2}$ are equivalent. Again it may be noted that if $\alpha_{1} / \beta_{1}>0$, then $\lambda_{1}=0$ implies $H_{1}=0$ only if $\sigma_{1}=1$. In other words, the Hicks and the Harrod classifications of neutral technical progress in the capital-gnods sector are equivalent only if the elasticity of substitution in the capital-goods sector equals unity.

With a number of results at our disposal, we can now proceed towards the analysis of relative stability in the presence of technical improvements.

II. Existence and Stability of the Short Run Equilibrium

In the short run capital stock, labor supply, and the level of technology are given. From equations (8) and (5), we obtain:

${ }^{5}$ This formula can be found in the apendices of Amano [2] and Takayama [10]. 
(28) $\rho_{1}=\frac{s k}{\omega+k_{1}}$

Then substituting equations (6) and (7) Into equation (28) yields

(29) $k=\frac{\left(\omega+k_{1}\right) k_{2}}{\omega+(1-s) k_{1}+s k_{2}}=\frac{a}{b}$

Differentiating equation (29) and substituting equation (16), we obtain:

(30) $k *=\frac{k_{2}}{a b}\left[\left(g+c \sigma_{1}+c \sigma_{2}\right) u^{*}+\left(c \lambda_{1}+e \lambda_{2}\right)\right]$

where

$$
\begin{aligned}
& g=s\left(k_{2}-k_{1}\right) \omega \\
& c=s\left(\omega+k_{2}\right) k_{1} \\
& e=\left(\omega+k_{1}\right)\left[\omega+(1-s) k_{1}\right]
\end{aligned}
$$

Let $g+c o_{1}+e r_{2}=D$ and $c \lambda_{1}+e \lambda_{2}=B$, and $\frac{k_{2}}{a b}=\frac{1}{R}>0$. Then equation (30) can be written as:

(31) $\mathrm{Rk} *=\omega * \mathrm{D}+\mathrm{B}$

As noted before, $B$ is zero in the short run, and since $R>0$, the relationship between $k^{\star}$ and $\omega^{\star}$ depends on the sign of $D$. It is evident that $k^{*}$ and $\omega^{*}$ will have the same sign only if $D>0$. Simflarly, since $c \sigma_{1}$ and $e y_{2}$, two of the three constituents of $D$, are positive, the relationship between $k^{*}$ and $\omega^{*}$ will be unique only if

(1) $g: 0$, or

(ii) $\mathrm{cr}_{1}+\mathrm{g} \geqslant 0$, or

(iii) en $2+g \geq 0$.

In case (i) $g ; 0$ means that $k_{2} \geqslant k_{1}$. In other words, if the consumptiongoods sector is at least as capital-intensive as the capital-goods sector, $k$ * and $\omega^{*}$ have the same sign. This condition in the literature on two-sector growth models is known as the capital-intensity condition, and we may conclude that if this condition is satisfied, $w$ is uniquely determined from $k$. Once $\omega$ is determined, the rest of the variables in the model can be easily shown 
to have positive and determinate values. Thus the capital-intensity condition is sufficient for the existence of the short-run competitive equilibrium.

$$
\text { In case (ii), } c \sigma_{1}+g \geqslant 0 \text { means that }
$$

$$
\therefore \geqslant\left[\frac{\omega}{\omega+k_{2}}\right]\left[\frac{k_{1}-k_{2}}{k_{1}}\right]
$$

From equation (10), we know that $\frac{\omega}{\omega+k_{2}}=E_{2}$.

Therefore inequality (32) becomes

$$
\sigma_{1} \geqslant B_{2} N \cdot 1
$$

where $N=\frac{\left(k_{1}-k_{2}\right)}{k_{1}}<1$.

From inequality (33), it is clear that if $\sigma_{1}$ is at least equal to $\beta_{2}$, the relative share of labor in the consumption-goods sector, inequality (11) will be satisfied and $k^{*}$ and $\omega^{*}$ w 111 have the same sign.

In case (111), $e^{t_{2}}+g \geqslant 0$ means that

$$
\sigma_{2} \geqslant \beta_{1}\left[\frac{\left(k_{1}-k_{2}\right) s}{1+(1-s) k_{1}}\right]
$$

It is clear that, for certain values of $s$, the condition that the elasticity of substitution in the consumption-goods sector be greater than or equal to the relative sliare of labor in the capital-goods sector satisfies inequality (34). If incquality (34) is satisfied, $D$ is greater than zero and $k *$ and $\omega *$ have the same sign. Once we obtain sufficient conditions for $D>0$, $w$ is uniquely determined from the given level of $k$ in the short-run, and once $w$ is uniquely determined, the rest of the variables, as stated before, are

${ }^{6}$ It can be easily seen that inequality (34) will be satisfied when

$$
\sigma_{2} \geqslant B_{1} \text { if } s \leqslant \frac{1+k_{1}}{2 k_{1}-k_{2}} \text {. }
$$

In [4] we have shown that this restriction is unnecessary if workers also save a part of their income. In any case, it can be shown that $\sigma_{2} \geqslant 1$ is a sufficient condition for inequality (34) to be satisfied. 
also uniquely determined. 7

III. Existence and Stablity of the Long-Run Equilibrium

Given that the competitive equilibrium is otable in each time period, the stability of the long-run equilibrium is determined by the behavior of the rate of growth of capital over time. Specifically, a growth model is said to be relatively stable if, when capital-stock is growing faster than labor, the system operates in such a way as to lower the rate of growth of capital, and vice-versa. If, in the limit, the rate of growth of capital, asymptotically approaches the exogenously determined growth rate of labor, the growth path so attained is called the balanced growth path. In this path capital and labor grow at the same constant rate and the capital/labor ratio remains constant over time. If the rate of growth of capital becomes constant before actually equalling the growth rate of labor, the growth path so attained has been called the equilibrium growth path. In this path labor and capital grow at constant but unequal rates and the capital/labor ratio may rise or decline over time. The process of capital accumulation In this model is described by equation ( 8 ), so that

$P_{1} Y_{1}=P_{1} d K=s r K$, or

(35) $\frac{d K}{K}=c=s v_{1}$

Here we assume that capital is everlasting so that there is no depreciation factor to worry about. ${ }^{8}$ Let $n$ be the constant rate of growth of labor. Then the growth process is described by:

${ }^{7}$ See Uzawa [8].

${ }^{8}$ Depreciation factor is ignored only for the sake of simplicity. In fact, depreciation by "suddendeath" can be easily introduced in our model. 
(36)

$$
k \star=G-L \star=s v_{1}-n \text {. }
$$

In the balanced growth path $G=s v_{1}=n$ or $k^{*}=0$, but in the equilibrium growth path, $G=n+\mu$ and $k \star+0$, where $\mu$ is a constant not equal to zero. In this way the balanced growth path becomes a special case of the equilibrium growth path when $\mu=0$. Differentiating equation (35), we have:

$$
\mathrm{C}^{*}=\mathrm{v}_{1} \text { * }
$$

Substituting $\omega^{*}$ from equation (19) Into equation (31) ylelds:

$$
v_{1} *=\alpha_{1}-\frac{B_{1}}{D}[R k *-B]
$$

whence

$$
G *=\alpha_{1}-\frac{\dot{B}}{D} \quad[R k *-B]
$$

where

$$
\begin{aligned}
& R=\frac{a b}{k_{2}}>0, D=8+c \sigma_{1}+c \sigma_{2}, \text { and } \\
& B=c \lambda_{1}+e \lambda_{2} .
\end{aligned}
$$

As suggested before, relative stability requires that if capital stock is growing faster than labor, the adjustment mechanism should be such as to lower the rate of growth of capital, and conversely. In other words, if $k \star \geqslant 0$, (i* $\leqslant 0$. From equation (39), it is clear that, if technical progress is ahsunt, $C_{*} \leqq 0$ when $k^{*}>0$ only if $D>0$. For then $a_{1}=B=0$. In the previous section, we have obtained the sufficient conditions under which $D>0$. Thus we may state our proposition I in this manner.

Proposition I: If technical progress is absent, then the sufficient conditions for relative stability in our model are: (1) the capitalIntensity condition holds, (2) $\sigma_{1} \geqslant \beta_{2}$, or (3) $\sigma_{2} \geqslant B_{1} \cdot 9$

\footnotetext{
${ }^{9}$ Given, of course, that the restriction shown in note 7 holds. In what follows, we will assume that this restriction holds. Otherwise the reader may prefer a more restrictive condition of $\sigma_{2} \geqslant 1$. For the sake of brevity these three separate conditions will be represented by the condition $D>0$.
} 
A. Hicks-Technical Progress in the Consumption-Goods Sector:

Let us now examine the conditions for relative stability in the presence of technical progress. First, consider the case in which Hickstechnical progress occurs in the conseumption-goods sector only. Here $a_{1}=\lambda_{1}=0$. If $\lambda_{2}=0$, that is, if technical progress in the consumptiongoods sector is Hicks-neutral, one can see from equation (39) that the conditions for relative stability remain unchanged.

Proposition II: If Hicks-neutral technical progress occurs in the consumption-goods sector, the necessary and sufficient condition for relative stability is that $D>0$. The growth process starting from any arbitrary capital/labor ratio approaches the balanced-growth path as is evident from the fact that $G *=0$ only when $k^{*}=0$.

If, however, $\lambda_{2} \neq 0$, that is, If Hicks-technical progress in $Y_{2}$ is non-neutral, the analysis becomes more complicated. Let equaltion (39) be written as:

$(40)^{10} G^{*}=\alpha_{1}-\frac{B}{D} 1\left[(8+c+e) k *-\left(c \lambda_{1}+e \lambda_{2}\right)\right]$

From equation (40) it is clear that when $\alpha_{1}=\lambda_{1}=0$, but $\lambda_{2} \neq 0$, then $G *=0$ only when

(41) $k *=E \dot{i}_{2}$, where $E=\frac{e}{g+c+e}<1$.

Equation (41) defines an equilibrium-growth path, because when $k^{\star}=E \lambda_{2}$, the

$10_{\text {By }}$ simple manipulation $1 t$ can be shown that $8+c+e=R$. Because

$$
\begin{aligned}
g+c+e & =\omega\left[s k_{2}+(1-s) k_{1}+\omega\right]+k_{1}\left[s k_{2}+(1-s) k_{1}+\omega\right] \\
& =\left[\omega+k_{1}\right]\left[s k_{2}+(1-s) k_{1}+\omega\right]=a b / k_{2}=R .
\end{aligned}
$$

Substituting $(g+c+e)$ for $R$ in equation (39) ylelds equation (40). 
rate of growth of capital becomes constant. In this path, capital and labor grow at constant but unequal rates, and the capital/labor ratio declines or rises over time depending on whether $\lambda_{2}<0$ or $\lambda_{2}>0$. Moreover, since $E<1$, a necessary condition ${ }^{11}$ for the existence of the equilibrium-growth path is that $k^{*}<: \lambda_{2} \mid$.

Let this equilibrium-growth path exist. Our next task is to see whether or not the growth process starting at any arbitrary capital/labor ratio actually converges to the path defined by equation (41). For this purpose, it is necessary to observe the behavior of $G$ when $k \star$ diverges from its equilibrium-growth path value. If at any point of time, $k^{\star} 11$ es above 1ts equilibrium-growth-path value, the system must operate in a way that $G$ declines, and vice-versa if the model is to be relatively stable. Let (42) $k \star=E \lambda_{2}+Z$

Where $z=0$. If at the start of the growth process $k * 11$ es above 1 ts value defined by the equilibrium-growth path, 2 is positive; in the opposite case it is negative. Substituting equation (42) in equation (40), we have, remembering that $\alpha_{1}=\lambda_{1}=0$ :

(43) $G *=-\frac{B_{1}}{D} \mathrm{ZR}$

where $R=g+c+e>0$. It may be observed from equation (43) that the necessary and sufficient concition for $G^{*} \leq 0$ when $2<0$ is that $D>0$.

Proposition III: If Hicks-technical progress in the consumption-goods sector is non-neutral, the necessary and sufficient condition for the growth process to converge to the equilibrium-growth path is that $D>0$. In this path, capital and labor grow at constant but unequal rates. If

$11 E=\frac{e}{8+c+e}=\frac{1}{1+\frac{s k_{2}}{\omega+(1-s) k_{1}}}<1$ 
Hicks-technical progress in the consumption-goods sector 18 capital-using, 1.e., If $\lambda_{2}>0$, the capital stock grows faster than labor by a constant rate; if it is capital-saving i.e., if $\lambda_{2}<0$, the capital stock grows slower than labor by a constant rate.

This proposition gains further clarification from Fig. 1 which is actually an adaptation from Fig. 5 in [3]. The rates of growth of capital and labor are measured along the vertical axis and time along the horizontal axis. The exogenously determined rate of growth of labor is given by on. If at the start of the growth process at time $t_{0}, G>n$, than $G$ declines over time, and conversely, till at time $t_{5}$ it comes to equal $n$ provided, of course that $D>0$, and technical progress 18 elther absent or is Hicks-neutral in $Y_{2}$. The time-path followed by $G$ is either $G_{1} A n^{*}$ or $G_{0} A n^{\star}$. The balanced-growth path is given by $n n *$, whereas the equilibrium growth path is given by $c^{*}$ if $\lambda_{2}>0$ or by FF* if $\lambda_{2}<0$. If at the start of the growth process $G=G_{1}>0 c$, then given that $D>0, G$ declines over time and comes to approach the equilibrium growth path either at $t_{4}$ or $t_{6}$ and thereafter continues to follow the equilibrium-growth path. The time-path followed by $G$, if $\lambda_{2}>0$, is $G_{1} B c^{\star}$; if $\lambda_{2}<0$, it is $G_{1} \mathrm{HF}^{\star}$. In the former case, capital-stock grows faster than labor by a constant rate $\mathrm{BJ}$ and the capital/labor ratio also grows at this rate; in the latter case, capital stock grows slower than labor by NH and the capital/labor ratio also declines at this rate. If, on the other hand, $G$ at the start of the growth orocess, lies below any of the two equilibrium-growth paths, the time-fath to be followed by it can be determined analogously.

\section{B. Hicks-Technical Progress in the Capital-Goods Sector:}

If technical progress occurs in the capltal-goods sector or both sectors then $\alpha_{1}>0$, so that from equation (39), $G^{*}=0$ only if 


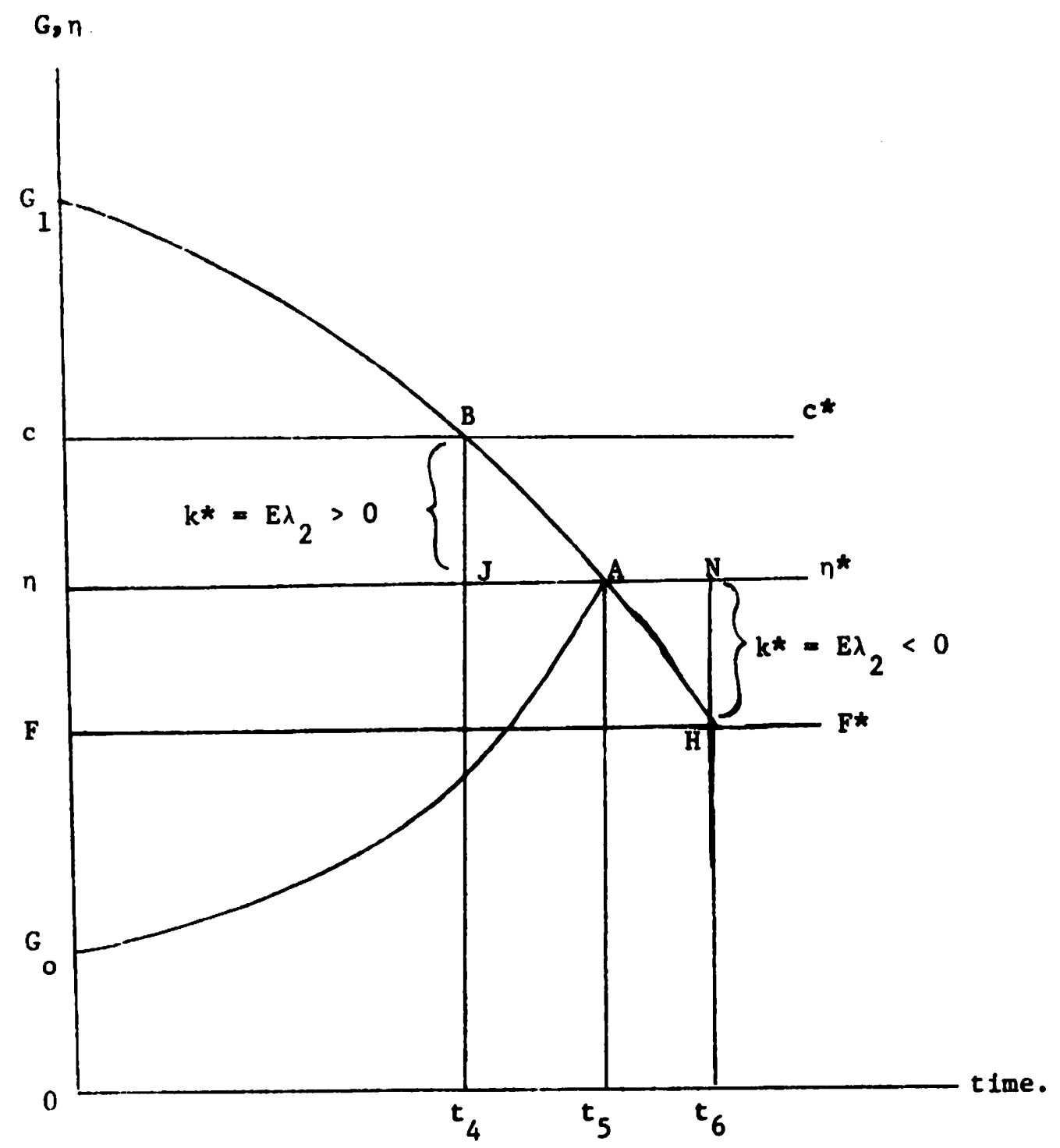

Figure 1 
(44) $k *=\frac{1}{R}\left[\alpha_{1} \frac{D}{B_{1}}+B\right]$

where $R>0$ and $B=c \lambda_{1}+e \lambda_{2}$.

In other words, even if Hicks-technical progress occurs in the capitalgoods sector or both sectors, there exists an equilibrium-growth path defined by equation (44), where capital and labor grow at constant but unequal rates and the capital/labor ratio increases or declines over time at a constant rate, depending on the sign of the expression in square bracketts in equation (44). 12 Let $k *$ at any point of time be given by:

(45) $k *=\frac{1}{R}\left[\alpha_{1} \frac{D}{B_{1}}+B\right]+Z$

where $Z \neq 0$. Substituting equation (45) in equation (44) again yields equation (43), namely

(43) $G \star=-\frac{B_{1}}{D} Z R$

Again it is evident from equation (43) that $G *$ and $Z$ move in the opposite direction only if $D>0$. In other words, if $Z>0$, that 1s, if $k *$ lies above 1 ts value defined by equation (44), G* declines, and vice-versa. Therefore, given that D $>0$, the growth process starting at any arbitrary capital/labor ratio converges to the equilibrium growth path defined by equation (44).

Proposition IV: If Hicks-technical progress occurs in the capital-goods sector or both sectors, then the necessary and sufficient condition for the uniqueness and stabllity of the equilibrium growth path defined by equation (44) is again that $D>0$. If technical progress in the capitalgoods sector or both sectors is Hicks-neutral, then, in the equilibrium

12 Whether or not $k *$ is constant is not apparent from equation (44). But since $k^{*}$ is the difference between $G$ and $n$, and since these two are constant, $k$ * must also be constant in the equilibrium-growth path. 
path, capital stock grows faster than labor by a constant rate. 13

Indeed, a sufficient condition for the capital stock to grow faster than labor in the equilibrium-growth path 18 that $B \geqslant 0$. If, however, $B<0$, there arises a possibility that $k^{\star}$ may be zero or negative, depending on whether

$$
\frac{\alpha_{1}}{B_{1}} \div-\frac{B}{D}
$$

If technical progress occurs in $Y_{1}$ alone, then a necessary condition for (46) to be satisfled is that $B=c \lambda_{1}<0$.

Proposition V: Given that $\alpha_{1} / B_{1}=-c \lambda_{1} / D$, and given also that $D>0$, the necessary condition for the existence of the balanced-growth path where $k *=0$ is that $\lambda_{1}<0$, that 1s, technical progress in the capitalgoods sector alone is Hicks-capital saving. 14

If, however, $\alpha_{1} / B_{1}<-c \lambda_{1} / D$ and $D>0$, the equilibrium-growth path will lie below the balanced-growth path and capital stock will grow slower than labor by a constant rate.

\section{Harrod-Technical Progress in the Consumption-Goods Sector:}

It has already been shown in section I that the definition of Harrodtechnical progress in the consumption-goods sector is equivalent to that of Hicks-technical progress. Thus we may simply conclude that propositions II and III concerning the effects of Hicks-neutral and non-neutral technical progress in the consumption-goods sector alone also apply to the case of

${ }^{13}$ This is because, here $B=0$ and $k *$ from equation (44) 18 positive. ${ }^{14}$ Even if $\lambda_{1}=0$, the balanced growth path may exist if $B=e \lambda_{2}<0$. In other words, the balanced-growth path may exist even if technical progress is $Y_{1}$ is Hicks-neutral, provided that technical progress in $y_{2}$ is Hickscapital saving. Thus, it is interesting to note that there 18 at least one case where the balanced-growth path exists and is stable even if technical progress in the capital-goods sector is Hicks-neutral. 
Harrod-technical progress in the same sector.

D. Harrod-Technical Progress in the Capital-Goods Sector:

The implications of Harrod-technical progress for relative stability can be explored simply by substituting $\lambda_{1}$ from equation (27a) in equation (40). Doing this substitution and some readjustment yield:

(47) $G^{*}=\frac{-{ }^{\beta} 1}{\bar{D}}\left[\left(k^{*}-\frac{\left.a_{1}\right)}{\beta_{1}} R-\left(\mathrm{cH}_{1}+\mathrm{eH}_{2}\right)\right]\right.$

where $R=g+c+e>0, D=g+c \sigma_{1}+e \sigma_{2}$ and $H_{1}$ is the Harrod measure of technical progress in the $1^{\text {th }}$ sector.

It may be observed from equation (47) that $G *=0$ only if

$$
k *=\frac{\alpha_{1}}{\beta_{1}}+\frac{\mathrm{cH}_{1}+\mathrm{eH}_{2}}{\mathrm{R}}
$$

In other words, there again exists an equilibrium growth path defined by equation (48) where capital and labor grow at constant but unequal rates. Consider first the case where technical progress in $Y_{1}$ alone is Harrod-neutral. Here $H_{1}=H_{2}=0$, but $\alpha_{1}>0$, so that $k^{*}=\alpha_{1} / \beta_{1}$. Let $k^{*}=\alpha_{1} / B_{1}+z$. Substituting this in equation (47) and remembering that $\mathrm{H}_{1}=\mathrm{H}_{2}=0$, we obtain

(43) $G *=-\frac{B_{1}}{D} \mathrm{ZR}$

Again we see from equation (43) that the necessary and sufficient condition for $G *$ and $Z$ to move in the opposite direction 18 that $D>0$. Proposition VI: If Harrod-neutrality occurs in the capital-goods sector alone, then the necessary and sufficlent condition for the growth process starting at any capital/labor ratio to converge to the equilibrium-growth path defined by equation (48) 18 that $D>0$. In th1s path capital stock grows faster than labor by a constant rate equal to $\alpha_{1} / \beta_{1}$, and the rate 
of profit remains constant. 15

It is evident from equation (48) that proposition VI remains valid even if Harrod-technical progress in $Y_{1}$ is non-neutral, or if it is neutral In both sectors or has any other combination in the two sectors so long as $\mathrm{cH}_{1}+\mathrm{eH}_{2}=0$.

Again there arises a possibility that $k^{*}=0$ if $\left(\mathrm{cH}_{1}+\mathrm{eH}_{2}\right)<0$. Thus we may derive:

Proposition VII: There exists a case where the growth process converges to the balanced-growth path when $D>0$, provided that $a_{1} / B_{1}=-\left(\mathrm{cH}_{1}+\mathrm{eH}_{2}\right) / \mathrm{R}$. In this path, capital and labor grow at a constant and equal rate inspite of Harrod-technical progress in any one or both sectors.

Again if $\alpha_{1} / \beta_{1}<-\left(\mathrm{cH}_{1}+\mathrm{eH}_{2}\right) / \mathrm{R}$, the equilibrium growth path, when D $>0$, lies below the balanced-growth path.

\section{Concluding Remarks}

It is intersting to see the similarity between the implications for relative stability of Hicks and Harrod technical progress. To begin with, the two-sector growth model is relatively stable without any additional restriction only if Hicks or Harrod neutrality occurs in the consumptiongoods sector alone. If Hicks or Harrod neutrality occurs in the capitalgoods sector or in both sectors, the balanced-growth path does not exist in efther case. The equilibrium growth path exists in both cases and the conditions for the relative stability of the model are also the same. Indeed, if the elasticity of factor substitution in each sector equals unity, the equilibrium growth paths with Hicks and Harrod neutrality occurring In $Y_{1}$

${ }^{15}$ Amano [2] and Takayama [10] have interpreted $\alpha_{1} / \beta_{1}$ as the rate of growth of output per man in the capital-goods sector when the capital/output ratio is kept constant. 
alone, or in both sectors colncide. ${ }^{16}$ It is well-known that the implications of Hicks and Harrod-neutrality for economic stab1lity in a one sector model are the same if the elasticity of substitution equals unity [See, Uzawa 9]. Our result that the Implications of Hicks and Harrod-neutrality in the capital-goods sector alone for relative stability are the same only if $\sigma_{1}=\sigma_{2}=1$ may then be considered as the two-sector model counterpart of the well-known result in the one sector model.

Finally we mention a result derived by Burmelster [5]. He concludes that the economy approaches the equilibrium-growth path in the presence of Harrod-technical progress if it 18 neutral and occurs at the same rate in both sectors, provided, of course, that the model without technical progress is stable. We have, however, shown in the preceeding section that the growth process converges to the equilibrium-growth, appropriately defined, even if (1) Harrod-neutrality occurs only in the capital-goods sectors, (11) 1t occurs in both sectors at unequal rates, and (111) Harrod-technical progress in one or both sectors is non-neutral.

${ }^{16}$ From equation (44) $k *=\left[\frac{{ }^{\alpha} 1}{B_{1}} D+B\right] \frac{1}{R}$ where $D=g+c \sigma_{1}+e \sigma_{2}$ and $R=g+c+e$. It is evident that if $B=0$ when $\lambda_{1}=\lambda_{2}=0, k *=\frac{\alpha_{1}}{\beta_{1}}$ if $\sigma_{1}=\sigma_{2}=1$. It may be seen that this is also the value of $k *$ in equation (48) if $H_{1}=H_{2}=0$. 
1. Amano, A., "A Further Note on Professor Uzawa's Two-Sector Model of Economic Growth," Review of Economic Studies, Vol. 31 (Apr11, 1964), 97-102.

2. Amano, A. "Determinants of Comparative Costs: A Theoretical Approach," 0xford Economic Papers, Vol. 16 (November, 1964), 389-400.

3. Batra, R., "Hicks and Harrod Neutral Technical Progress and the Relative Stability of a Two-Sector Growth Model with Fixed Coefficients," Journal of Political Economy, (forthcoming) in Jan./Feb., 1970.

4. Batra, R., "The Savings-Hypothesis, Factor Substitution and the Relative Stability in a Two-Sector Model of Economic Growth," mimeographed.

5. Burmeister, E., "The Role of the Jacobian Determinant in the TwoSector Mode1"' Internation1 Econom1c Review, Vo1. 9 (June, 1968), 195-203.

6. Drandakis, E. M., "Factor Substitution in the Two-Sector Growth Model," Review of Economic Studies, Vol. 30 (October, 1963), 217-28.

7. Findlay, R., "Neutral Technical Progress and the Relative Stability of Two-Sector Growth Mode1s," International Economic Review, Vol. 8 (February, 1967), 109-15.

8. Uzawa, H., "On a Two-Sector Model of Economic Growth" Review of Economic Studies, Vol. 29 (October, 1961), 40-47.

9. Uzawa, H., "Neutral Inventions and the Stability of Growth Equilibrium," Review of Economic Studies, Vo1. 28 (February, 1961), 117-24.

10. Takayama, A., "On a Two-Sector Model of Econom1c Growth with Technical Progress: A Comparative Statics Analysis," Review of Economic Studies, Vol. 32, (July, 1965), 251-62. 